\section{SYNLETT Spotlight 276}

This feature focuses on a reagent chosen by a postgraduate, highlighting the uses and preparation of the reagent in current research

\title{
Pyridinium Hydrobromide Perbromide: A Versatile Reagent in Organic Synthesis
}

\author{
Compiled by Shu-Hong Yang \\ Shu-Hong Yang was born in Shandong, P. R. of China. She re- \\ ceived her Bachelor degree in 2000 from Hebei University of Sci- \\ ence and Technology, P. R. of China. Thereafter, she spent seven \\ years working at Hebei Shijiazhuang Pharmaceutical Group Co., \\ Ltd., in Shijiazhuang, P. R. of China. She is currently working as a \\ postgraduate in the research group of Professor Zhan-Hui Zhang at \\ Hebei Normal University. Her research interest focuses on the de- \\ velopment of new synthetic methodologies for green chemistry. \\ The College of Chemistry \& Material Science, Hebei Normal Uni- \\ versity, 050016 Shijiazhuang, P. R. of China \\ E-mail: yang_shuhong@126.com
}

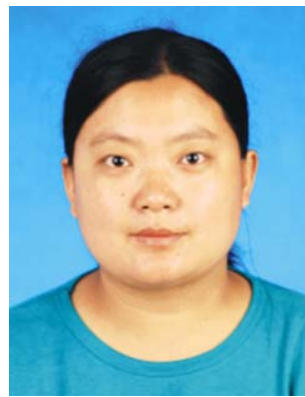

\section{Introduction}

Pyridinium hydrobromide perbromide (PHPB) has been extensively used in organic synthesis as a selective brominating reagent for alkenes, ${ }^{1-5}$ alkanes, ${ }^{6}$ arenes, ${ }^{7}$ ketones,${ }^{7,8}$ anilines, ${ }^{9}$ aromatic ethers, ${ }^{10} \mathrm{~N}$-heterocycles,${ }^{11}$ and oxidizing reagents. ${ }^{12,13}$ PHPB forms red prismatic crystals and its melting point is at $134{ }^{\circ} \mathrm{C}$. Further, it is easy to handle, stable and environmentally safe. ${ }^{14}$ PHPB has been used for regioselective heterocyclization of ortho-cyclohexenyl phenols ${ }^{15}$ and ipsobromodeformylation in $o$-hydroxy and $o$-methoxy substituted aromatic aldehydes. ${ }^{16}$ It was also found to be a useful catalyst for the chemoselective deprotection of primary TBS and TES ethers, ${ }^{17}$ hydrolysis of thioacetals, ${ }^{18}$ and hydroamination of activated styrenes. ${ }^{19}$

Pyridinium hydrobromide perbromide is commercially available, but it can be readily prepared by adding one mole of bromine to one mole of pyridine in $48 \%$ hydrobromic acid solution. ${ }^{14}$

\begin{abstract}
s
(A) Selective Oxidation of Thiols and Sulfides into the Corresponding Disulfides and Sulfoxides: Lakouraj et al. showed that PHPB is an efficient and chemoselective reagent for the oxidation of aliphatic and aromatic thiols into the corresponding disulfides under solvent-free conditions at room temperature. A further oxidation or bromination of the aromatic ring did not proceed under these oxidative conditions. Furthermore, organic sulfides can be readily oxidized into the corresponding sulfoxides in tetrahydrofuran and water at room temperature. ${ }^{20}$
\end{abstract}

(B) Esterification of Aldehydes and Alcohols: PHPB can be applied for the direct esterification of aldehydes and alcohols in water at room temperature. A variety of aliphatic alcohols were also converted into the corresponding Tishchenko-like dimeric esters under the same reaction conditions. In contrast to aliphatic alcohols, secondary alcohols were oxidized to give the corresponding ketones by $\mathrm{PHPB} \cdot \mathrm{H}_{2} \mathrm{O} .^{21}$

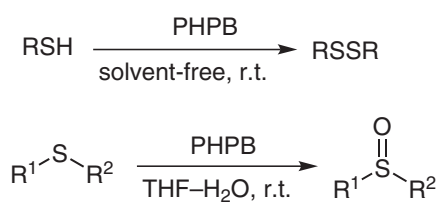

(C) One-Pot Synthesis of $\omega$-Bromoesters from Aromatic Aldehydes and Diols: A convenient and practical method for the one-pot synthesis of $\omega$-bromoesters from aromatic aldehydes and diols in the presence of PHPB as brominating reagent and triethoxymethane as dehydrating agent has been developed. ${ }^{22}$

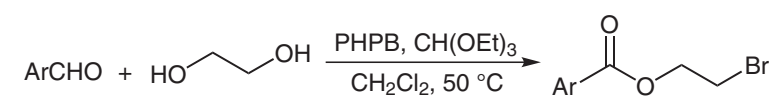

SYNLETT 2009, No. 8, pp 1351-1352

Advanced online publication: 07.05.2009

DOI: 10.1055/s-0029-1216645; Art ID: V28208ST

(c) Georg Thieme Verlag Stuttgart · New York 
(D) Conversion of Thioamides into Amides: A mild and selective method for the transformation of thioamides and thioureas into the corresponding carbonyl compounds using PHPB has been developed by Lakouraj and Ghodrai. Under the same condition, acetals and ketales remained unchanged; the bromination of aromatic rings did not proceed. ${ }^{23}$

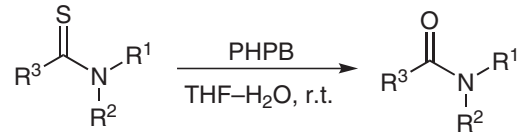

(E) Sequential Bromination-Rearrangement of Push-Pull Thiazolidines: One of the best methods for the synthesis of push-pull thiazolidines with two exocyclic double bonds is the regiospecific bromination-rearrangement of 5-substituted 2-alkylidene-4-oxothiazolidine derivatives induced by $\mathrm{PHPB}$. The reaction was performed in acetonitrile as a one-pot procedure to yield the products in nearly quantitative yields. ${ }^{24}$
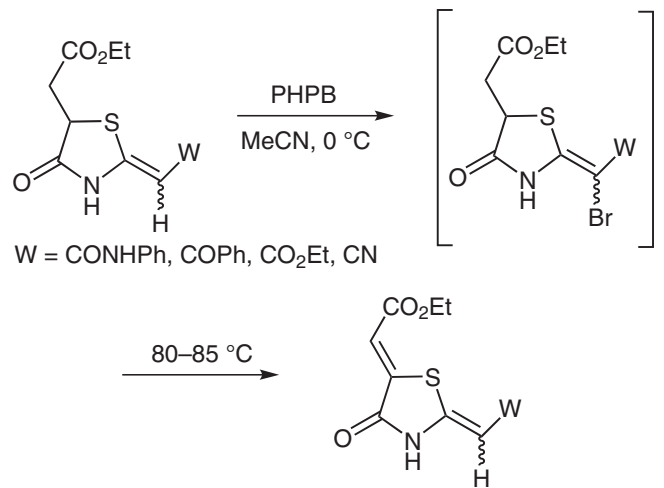

(F) Synthesis of Oxazolines and Imidazolines: Sayama reported a new, mild and chemoselective method for the synthesis of 2-substituted oxazolines from aromatic aldehydes and 2-aminoethanol using PHPB in water at room temperature. Aromatic aldehydes were also converted into 2-imidazolines in the presence of ethylenediamine under the same reaction conditions. ${ }^{25}$

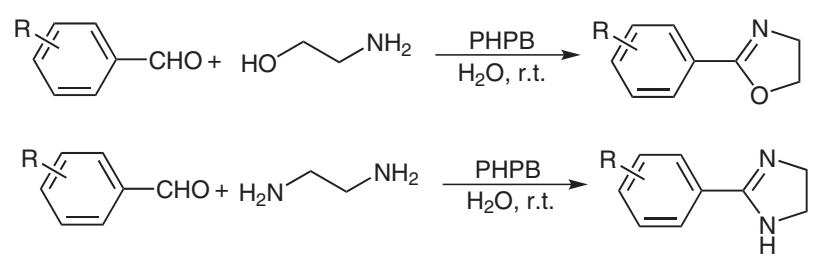

(G) The Aziridination of Olefins: In addition to the previous cases, Sudalai and co-workers showed that PHPB is a versatile catalyst in the aziridination of a variety of olefins using chloramine-T trihydrate $\left(\mathrm{TsNClNa} \cdot 3 \mathrm{H}_{2} \mathrm{O}\right)$ as a nitrogen source. ${ }^{26}$

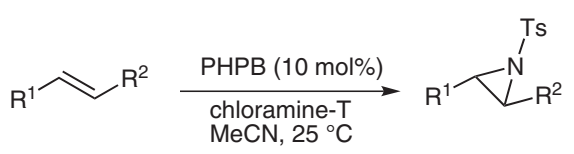

\section{References}

(1) Li, C.; Prichard, M. N.; Korba, B. E.; Drach, J. C.; Zemlicka, J. Bioorg. Med. Chem. 2008, 16, 2148.

(2) Robins, M. J.; Miranda, K.; Rajwanshi, V. K.; Peterson, M. A.; Andrei, G.; Snoeck, R.; De Clercq, E.; Balzarini, J. J. Med. Chem. 2006, 49, 391.

(3) Díaz-Sánchez, B. R.; Iglesias-Arteaga, M. A.; MelgarFernández, R.; Juaristi, E. J. Org. Chem. 2007, 72, 4822.

(4) Sasaki, S.-i.; Mizoguchi, T.; Tamiaki, H. J. Org. Chem. 2007, 72, 4566.

(5) Mphahlele, M. J.; Moekwa, T. B. Org. Biomol. Chem. 2005 , 3, 2469.

(6) Shandura, M. P.; Poronik, Y. M.; Kovtun, Y. P. Dyes Pigments 2007, 73, 25.

(7) Levin, Y.; Hamza, K.; Abu-Reziq, R.; Blum, J. Eur. J. Org. Chem. .

(8) Cabaj, J. E.; Kairys, D.; Benson, T. R. Org. Process Res. Dev. 2007, 11, 378 .

(9) Reeves, W. P.; King, R. M. II Synth. Commun. 1993, 23, 855.

(10) Reeves, W. P.; Lu, C. V.; Schulmeier, B.; Jonas, L.; Hatlevik, O. Synth. Commun. 1998, 28, 499.

(11) Miki, Y.; Umemoto, M.; Nakamura, M.; Hibino, H.; Ohkita, N.; Kato, A.; Aoki, Y. Heterocycles 2006, 68, 1893.
(12) Ali, M. H.; Stricklin, S. Synth. Commun. 2006, 36, 1779.

(13) Aneja, M.; Kothari, S.; Banerji, K. K. J. Phys. Org. Chem. 2001, 14, 650 .

(14) Djerassi, C.; Scholz, C. R. J. Am. Chem. Soc. 1948, 70, 417.

(15) Majumdar, K. C.; Kundu, A. K. Can. J. Chem. 1995, 73, 1727.

(16) Córdoba, R.; Plumet, J. Tetrahedron Lett. 2002, 43, 9303.

(17) Martinez-Solorio, D.; Jennings, M. P. Tetrahedron Lett. 2008, 49, 5175.

(18) Bates, G. S.; O'Doherty, J. J. Org. Chem. 1981, 46, 1745.

(19) Talluri, S. K.; Sudalai, A. Org. Lett. 2005, 7, 855.

(20) Lakouraj, M. M.; Ghodrati, K. Phosphorus Sulfur Silicon 2008, 183, 1432.

(21) Sayama, S.; Onami, T. Synlett 2004, 2739.

(22) Aoyama, T.; Takido, T.; Kodomari, M. Tetrahedron Lett. 2005, 46, 1989.

(23) Lakouraj, M. M.; Ghodrati, K. Monatsh. Chem. 2008, 139 , 549.

(24) Markovic, R.; Baranac, M.; Dzambaski, Z. Heterocycles 2004, 63, 851 .

(25) Sayama, S. Synlett 2006, 1479.

(26) Ali, S. I.; Nikalje, M. D.; Sudalai, A. Org. Lett. 1999, 1, 705. 